\title{
Hidden renal disease in a female patient with long-lasting isolated gestational proteinuria followed by hypertension
}

\author{
Kosuke Kawabata ${ }^{1}$, Rina Akaishi ${ }^{2}$, Ayako Nozaki ${ }^{1}$, Osamu Sato ${ }^{1}$, Kaoru Hanatani ${ }^{1}$, \\ Hisanori Minakami ${ }^{2 \#}$ \\ ${ }^{1}$ Department of Obstetrics and Gynecology, Tomakomai City Hospital, Tomakomai, Japan \\ ${ }^{2}$ Department of Obstetrics, Hokkaido University Graduate School of Medicine, Sapporo, Japan \\ Email: " minasho@med.hokudai.ac.jp
}

Received 20 October 2013; revised 15 November 2013; accepted 21 November 2013

Copyright (C) 2013 Kosuke Kawabata et al. This is an open access article distributed under the Creative Commons Attribution License, which permits unrestricted use, distribution, and reproduction in any medium, provided the original work is properly cited.

\begin{abstract}
Background: The prevalence of asymptomatic renal scarring, such as a focal segmental glomerulosclerosis (FSGS), was suggested to be high in women who develop preeclampsia. FSGS is a risk factor for endstage renal disease. Objective: To document preeclamptic women with proteinuria that developed eight weeks prior to hypertension with confirmed FSGS postpartum. Case: A 20-year-old nulliparous Japanese woman with a negative dipstick test result at gestational week (GW) 18 exhibited proteinuria 1+ on dipstick test at GW 22. Proteinuria determined from the random urine protein to creatinine ratio $(\mathrm{P} / \mathrm{Cr}, \mathrm{g} / \mathrm{g})$ was increased from 3.7 at GW 26 to 4.6 and 8.9 at GW 28 and 30, respectively. She developed hypertension (142/66 $\mathrm{mmHg})$ at GW 30 . Due to increased edema, emergency cesarean section was performed at GW 33. She gave birth to an otherwise healthy female small-for-gestational-age infant, weighing 1290 g. Postpartum course was uneventful except for persisting proteinuria: $\mathrm{P} / \mathrm{Cr}$ of 9.8 just before delivery decreased to 3.6 and 1.7 on postpartum weeks 9 and 17, respectively. Renal biopsy on postpartum week 13 revealed FSGS in this patient. Conclusion: Hidden FSGS may have manifested as preeclampsia in this patient. This case highlighted the need to determine the prevalence of asymptomatic FSGS among women who later develop preeclampsia.
\end{abstract}

Keywords: Proteinuria; Nephrotic Syndrome; Preeclampsia; Differential Diagnosis

"Conflict of interest statement: We declare that we have no conflicts of interest in connection with this paper.

${ }^{\#}$ Corresponding author.

\section{INTRODUCTION}

Although proteinuria had been thought to be a late sign in the clinical course of preeclampsia [1], some women with preeclampsia develop proteinuria first and then later develop hypertension $[2,3]$. As degree of proteinuria in pregnancy increases with advancing gestation [2], the amount of protein loss in the urine may be greater in women with early development of proteinuria. Women with preeclampsia in whom proteinuria is severe enough to meet the criteria for nephrotic syndrome have a high prevalence of underlying renal disease, such as focal segmental glomerulosclerosis (FSGS) [4]. Therefore, heavy proteinuria may precede the development of hypertension in such preeclamptic women with FSGS.

Here, we present a woman who developed proteinuria 8 weeks prior to the development of hypertension and had postpartum renal biopsy-proven FSGS to highlight the need to determine the prevalence of unrecognized FSGS in women who later develop preeclampsia. The patient gave informed consent to this report.

\section{CASE REPORT}

A 20-year-old nulliparous Japanese woman with negative dipstick test results regarding proteinuria at gestational week (GW) 18 exhibited proteinuria of $1+$ on dipstick test at GW 22. Her medical history was unremarkable except for childhood proteinuria, for which she received no detailed examinations. The proteinuria assessed with random urine protein to creatinine ratio $(\mathrm{P} / \mathrm{Cr}, \mathrm{g} / \mathrm{g})$ increased from 3.7 at GW 26 to 4.6 and 8.9 at GW 28 and 30 , respectively, with generalized edema. She developed hypertension $(142 / 66 \mathrm{mmHg})$ at $\mathrm{GW} 30$ and was referred to us at GW 31 with diagnoses of preeclampsia and nephrotic syndrome. Increased edema (maternal weight gain of $2.7 \mathrm{~kg}$ in the last antenatal 13 days) prompted us 
to perform emergency cesarean section at GW 33. She gave birth to a female small-for-gestational age infant, weighing $1290 \mathrm{~g}$, with Apgar scores of 8 and 9 at 1 and 5 min, respectively. Postpartum course was uneventful except for persisting proteinuria: the $\mathrm{P} / \mathrm{Cr}$ of 9.8 just before delivery decreased to 3.6 and 1.7 on postpartum weeks 9 and 17, respectively. Renal biopsy on postpartum week 13 revealed FSGS in this patient (Figure 1).

\section{DISCUSSION}

From the prospective viewpoint, this case was unusual as simple preeclampsia with respect to long-lasting isolated gestational proteinuria (approximately 8 weeks) before the development of hypertension and heavy proteinuria. Time interval after the appearance of significant proteinuria defined as random urine protein concentration $\geq 25$ $\mathrm{mg} / \mathrm{dL}$ until the development of hypertension within 2 weeks in more than $80 \%$ of women and the mean (SD) proteinuria on the day of delivery was $3.8 \pm 3.7 \mathrm{~g}$ /day for 19 women with proteinuria preceding preeclampsia [2]. The patient recalled a history of proteinuria during childhood. All of these findings suggested hidden preexisting renal disease and the patient was found to have FSGS. Most experienced obstetricians may have suspected underlying renal disease in this patient. However, no clinical guidelines are available at present regarding which patients with preeclampsia should undergo detailed examinations to detect possible underlying renal disease.

The patient described here was found to have FSGS postpartum. It was unknown whether the FSGS was present before the establishment of pregnancy in this patient. Biopsy-proven FSGS lesions were frequently seen in preeclamptic women with nephrotic syndrome in a study by Nishimoto et al. [4] in which the authors considered that most FSGS lesions were induced by pregnancy itself and were reversible after delivery. However, Özlü et al. [5] recently proposed that asymptomatic, unrecognized renal scars caused by urinary tract infections in childhood become symptomatic as preeclampsia in pregnancy, suggesting that the primary underlying problem in the development of preeclampsia may lie in the kidneys in a greater proportion of cases than is generally believed. This hypothesis is interesting as FSGS lesions are very common in children and adults with reflux nephropathy [6]; microproteinuria is the earliest clinical manifestation of FSGS [6]; the risk of preeclampsia is 7.6-fold higher in women with known renal scars caused by urinary tract infection compared to controls [7]; FSGS is a histological entity characterized by podocyte (glomerular epithelial cell) injury and podocyturia occurs in most patients with FSGS [8]; and podocyturia in the second trimester is superior to angiogenic markers, such as endoglin, placental growth factor, and soluble FMS-like tyrosine

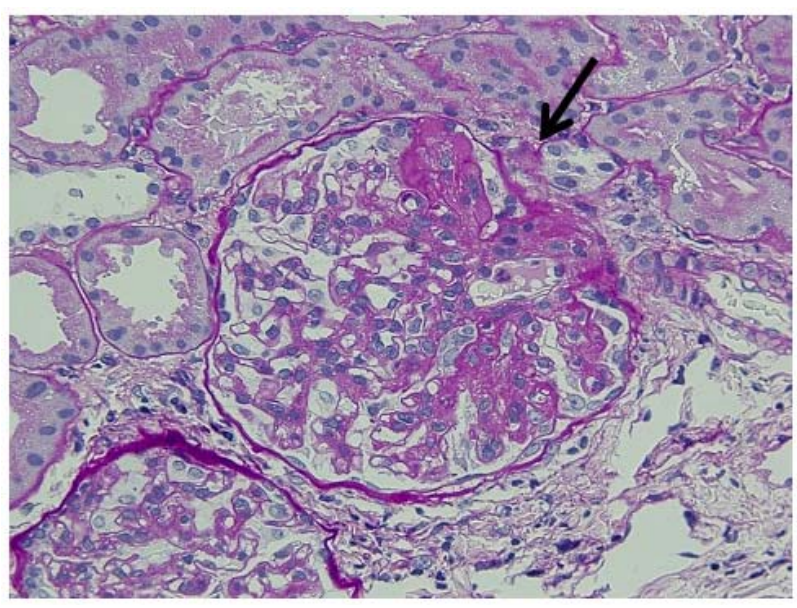

Figure 1. Microscopic findings $(\times 40)$. The arrow indicates a glomerulus characteristic of focal segmental glomerulosclerosis in this case.

kinase receptor-1 for prediction of the development of preeclampsia [9]. Therefore, the primary underlying problem may lie in the kidneys in a greater proportion of cases with preeclampsia, especially among women who first develop proteinuria. In addition, among 14 patients with preeclamptic Turkish women with persistent proteinuria after delivery, biopsy-proven underlying renal diseases were present in 10 patients: membranoproliferative glomerulonephritis in four (29\%), IgA nephropathy in four $(29 \%)$, FSGS in one and amyloidosis in one in results of a recent study by Unverdi et al. [10].

\section{CONCLUSION}

In conclusion, the present case exhibited long-lasting and heavy isolated gestational proteinuria and subsequently developed hypertension. We speculated that asymptomatic, preexisting FSGS may have manifested as preeclampsia in this patient. Asymptomatic FSGS may worsen during and after pregnancy, as seen in this study, and FSGS is a risk factor for end-stage renal disease. This case highlighted the need to determine the prevalence of asymptomatic FSGS among women who later developed preeclampsia.

\section{REFERENCES}

[1] Chesley, L.C. (1985) Diagnosis of preeclampsia. Obstetrics \& Gynecology, 65, 423.

[2] Morikawa, M., Yamada, T., Yamada, T., Cho, K., Yamada, H., Sakuragi, N., et al. (2008) Pregnancy outcome of women who developed proteinuria in the absence of hypertension. Journal of Perinatal Medicine, 36, 419-424. http://dx.doi.org/10.1515/JPM.2008.062

[3] Yamada, T., Yamada, T., Morikawa, M., Takeda, M., Nishida, R., Akaishi, R. and Minakami, H. (2011) Iso- 
lated proteinuria as an initial sign of severe preeclampsia. Open Journal of Obstetrics and Gynecology, 1, 13-16. http://dx.doi.org/10.4236/ojog.2011.12003

[4] Nishimoto, K., Shiiki, H., Nishino, T., Kimura, T., Sasaki, Y., Yamasaki, M., et al. (1999) Glomerular hypertrophy in preeclamptic patients with focal segmental glomerulosclerosis. A morphometric analysis. Clinical Nephrology, 51, 209-219.

[5] Özlü, T., Alçelik, A., Çalısßkan, B. and Dönmez, M.E. (2012) Preeclampsia: Is it because of the asymptomatic, unrecognized renal scars caused by urinary tract infections in childhood that become symptomatic with pregnancy? Medical Hypotheses, 79, 653-655. http://dx.doi.org/10.1016/j.mehy.2012.08.002

[6] Morita, M., Yoshiara, S., White, R.H. and Raafat, F. (1990) The glomerular changes in children with reflux nephropathy. The Journal of Pathology, 162, 245-253. http://dx.doi.org/10.1002/path.1711620311

[7] McGladdery, S.L., Aparicio, S., Verrier-Jones, K., Roberts, R. and Sacks, S.H. (1992) Outcome of pregnancy in an Oxford-Cardiff cohort of women with previous bacte- riuria. Quarterly Journal of Medicine, 83, 533-539.

[8] Nakamura, T., Ushiyama, C., Suzuki, S., Hara, M., Shimada, N., Ebihara, I., et al. (2000) The urinary podocyte as a marker for the differential diagnosis of idiopathic focal glomerulosclerosis and minimal-change nephrotic syndrome. American Journal of Nephrology, 20, 175-179. http://dx.doi.org/10.1159/000013580

[9] Craici, I.M., Wagner, S.J., Kent, R., Bailey, K.R., Fitz-Gibbon, P.D., Wood-Wentz, C.M., et al. (2013) Podocyturia predates proteinuria and clinical features of preeclampsia: Longitudinal prospective study. Hypertension, 61, 1289-1296. http://dx.doi.org/10.1161/HYPERTENSIONAHA.113.01 $\underline{115}$

[10] Unverdi, S., Ceri, M., Unverdi, H., Yilmaz, R., Akcay, A. and Duranay, M. (2013) Postpartum persistent proteinuria after preeclampsia: A single-center experience. Wiener Klinische Wochenschrift, 125, 91-95. http://dx.doi.org/10.1007/s00508-013-0320-8 